\title{
The effect of pterygium surgery on contrast sensitivity and corneal topographic changes
}

This article was published in the following Dove Press journal:

Clinical Ophthalmology

16 April 2010

Number of times this article has been viewed

\section{Joo Youn Oh}

Won Ryang Wee

Department of Ophthalmology, Seoul National University Hospital, Seoul, Korea
Correspondence:Won Ryang Wee Department of Ophthalmology, Seoul National University College of Medicine, 28 Yeongeon-dong Jongno-gu, Seoul I I 0-744, Korea

Tel +82 2-2072-2435

Fax +82 2-74I-3187

Email wrwee@snu.ac.kr
Purpose: To investigate the effect of pterygium surgery on corneal topography and contrast sensitivity.

Patient and methods: The IRB approved this prospective, nonrandomized, self-controlled study. Computerized videokeratography (Orbscan II) was performed in 36 patients with primary pterygia, both before and 1 month after pterygium excision with limbal-conjunctival autografting. The topographic parameters were compared. Spatial contrast sensitivity testing was performed using VCTS 6500. Differences between preoperative and postoperative values were evaluated statistically.

Results: The mean Sim K astigmatism and irregularity index, significantly decreased after pterygium surgery. The mean refractive power significantly increased after the operation. The "with-the-rule" astigmatism induced by pterygium became "against-the-rule" astigmatism after pterygium removal $(P=0.041)$. The contrast sensitivity of 6,12 , and 18 cycles per degree, significantly increased from $1.55 \pm 0.28,0.97 \pm 0.47$, and $0.29 \pm 0.16$ to $1.72 \pm 0.18,1.21 \pm 0.44$, and $0.65 \pm 0.48$, respectively $(P=0.007,<0.001,<0.001$, respectively).

Conclusions: Pterygium surgery significantly reduces corneal topographic astigmatism and improves contrast sensitivity.

Keywords: corneal topography, visual acuity

\section{Introduction}

Pterygium is an ocular pathology seen frequently in ophthalmology practice. Large pterygia occluding the visual axis decrease visual acuity. However, even before entering the optical zone, an advancing pterygium can cause visual impairment by locally flattening the cornea and inducing with-the-rule astigmatism. ${ }^{1-5}$ Previous reports have demonstrated that the topographic changes in the cornea and visual impairment induced by pterygia can be reversed following removal. ${ }^{2-6}$ However, no investigators have reported the effect of pterygium surgery on optical qualities, such as contrast sensitivity, in addition to visual acuity and topographic changes. Hence, we performed this study in order to investigate the effect of pterygium surgery on contrast sensitivity and corneal topography.

\section{Patients and methods \\ Patients}

This prospective, nonrandomized, self-controlled trial included 36 patients (36 eyes) with primary pterygia. Patients with a history of ocular surgery, ocular trauma, contact lens wear, corneal scarring, or anterior segment diseases other than pterygium, 
were excluded from the study. Cosmetic problems, ocular irritation, and visual loss induced by pterygium were accepted as indications for surgery. All pterygia were located nasally.

\section{Surgical procedures}

All surgeries were performed by a single surgeon (Oh JY) using the same technique. After topical anesthesia was achieved, the corneal epithelium $1 \mathrm{~mm}$ anterior to the head of the pterygium was scraped off with a \#69 Beaver blade (Becton Dickinson and Co, Franklin Lakes, NJ, USA), and the pterygium body was pulled, peeled, and excised with a blade and Vannas scissors (Katena Products Inc., Denville, NJ, USA). Remnants over the cornea were shaved. The subconjunctival tissue under the body of the pterygium was removed. In cases of severe bleeding, cauterization of bleeding vessels was minimally applied. After the pterygium mass was removed, a limbal-conjunctival autograft was procured from the superior conjunctiva; the graft dissection was extended approximately $0.5 \mathrm{~mm}$ into clear cornea to include the Vogt palisades and limbal stem cells. This graft was moved to cover the defective area and was secured with 10-0 nylon sutures. The limbal end of the autograft was placed directly over the limbal area of the surgical bed. After surgery, a therapeutic contact lens was applied until corneal reepithelialization was completed. The sutures were removed under the operating microscope after conjunctival epithelialization occurred.

Postoperatively, patients were treated with topical 0.5\% levofloxacin (Cravit ${ }^{\circledR}$; Santen Pharmaceutical Co., Ltd., Osaka, Japan) qid, 1\% prednisolone acetate (Pred forte ${ }^{\circledR}$; Allergan, Inc., Irvine, CA, USA) qid, and autologous serum q 2 hours for two weeks. Autologous serum was prepared by taking $20 \mathrm{~mL}$ of peripheral blood from the patient using aseptic technique. The blood was then centrifuged for $5 \mathrm{~min}$ at 1500 revolutions/minute. The serum was separated and was diluted to $20 \%$ with sterile saline. The solution was then put into a bottle with ultraviolet light protective coating on the surface. Patients were instructed to store the eye drops in the freezer compartment of a domestic refrigerator for no more than 3 months.

\section{Examination of corneal topography and contrast sensitivity}

All patients underwent examinations one week before and one month after pterygium surgery. The best-corrected visual acuity (BCVA) was measured using the logMAR scale. Computerized videokeratography (Orbscan ${ }^{\circledR}$ IIz; Bausch and Lomb Inc., Rochester, NY, USA) was obtained, and the following topographic parameters were noted: simulated keratometry (Sim K) astigmatism; irregularities and mean refractive powers in the central 3 and $5 \mathrm{~mm}$ zones; and steep astigmatic axes. Spatial contrast sensitivity testing was performed using the VCTS 6500 (Vistech Consultants, Inc., Dayton, OH, USA) under mesopic room conditions; that is, a dim light with a chart luminance of 220 lux. The testing distance was 3 meters. Measurements were carried out monocularly with spectacle correction. Contrast sensitivity was tested at the spatial frequencies of $1.5,3,6,12$, and 18 cycles per degree (cpd). All contrast sensitivity data were converted to logarithmic units and log contrast sensitivity values, and the before and after surgery values were compared. All measurements were performed by experts who were blinded.

\section{Statistical analysis}

Data were expressed as means \pm standard deviation. Comparisons between the preoperative and postoperative values were made through the paired $t$-test or the nonparametric Mann-Whitney $U$ test using SPSS software (version 12.0; SPSS Inc., Chicago, IL, USA). Differences were considered statistically significant at $P<0.05$.

\section{Results}

$17(47.2 \%)$ of the 36 patients were men, and 19 (52.8\%) were women. Patient ages ranged from 27 to 79 years (mean $55.3 \pm$ 11.4 years). Neither complications nor recurrences developed during the follow-up period. The mean follow-up period was 6.3 months (range 1 to 9 months). The BCVA and topographic variables before and after pterygium surgery are shown in Table 1. There were no significant differences in BCVA before and after surgery. However, the mean Sim K astigmatism and

Table I Clinical and topographic variables before and after pterygium surgery

\begin{tabular}{llll}
\hline Parameter & $\begin{array}{l}\text { Preoperative } \\
\text { mean } \pm \text { SD }\end{array}$ & $\begin{array}{l}\text { Postoperative } \\
\text { mean } \pm \text { SD }\end{array}$ & P value \\
\hline $\begin{array}{l}\text { BCVA (logMAR) } \\
\begin{array}{l}\text { Topographic indices } \\
\text { (diopters) }\end{array}\end{array}$ & $0.16 \pm 0.38$ & $0.10 \pm 0.26$ & $\mathrm{~ns}$ \\
$\begin{array}{l}\text { Sim K astigmatism } \\
\text { Irregularity }\end{array}$ & $3.08 \pm 2.03$ & $1.22 \pm 0.78$ & $0.00 \mathrm{I}$ \\
$(3 \mathrm{~mm})$ & $3.49 \pm 1.66$ & $1.95 \pm 1.08$ & $0.00 \mathrm{I}$ \\
$\begin{array}{l}\text { Irregularity } \\
(5 \mathrm{~mm})\end{array}$ & $5.46 \pm 2.95$ & $\mathrm{I} .78 \pm 0.92$ & $<0.00 \mathrm{I}$ \\
$\begin{array}{l}\text { Mean refractive power } \\
(3 \mathrm{~mm})\end{array}$ & $43.2 \pm 1.17$ & $44.5 \pm 1.34$ & 0.002 \\
$\begin{array}{l}\text { Mean refractive power } \\
(5 \mathrm{~mm})\end{array}$ & $43.0 \pm 1.05$ & $43.8 \pm 1.33$ & $<0.00 \mathrm{I}$ \\
\hline
\end{tabular}

Abbreviations: BCVA, best-corrected visual acuity; ns, not significant. 
Table 2 The changes in Sim K astigmatism after surgery according to the preoperative Sim K astigmatism value

\begin{tabular}{lllll}
\hline $\begin{array}{l}\text { Preoperative } \\
\text { Sim K astigmatism (diopters) }\end{array}$ & No. of eyes & $\begin{array}{l}\text { Preoperative } \\
\text { (Mean } \pm \text { SD) }\end{array}$ & $\begin{array}{l}\text { Postoperative } \\
\text { (Mean } \pm \text { SD) }\end{array}$ \\
\hline$<2$ & 15 & $0.77 \pm 0.37$ & $1.28 \pm 1.66$ & \\
$\geq 2$ & 21 & $4.21 \pm 1.58$ & $1.89 \pm 2.66$ & 0.237 \\
\hline
\end{tabular}

topographic irregularity values significantly decreased after pterygium surgery. The mean refractive power significantly increased after the operation. The respective values of the study parameters before and after pterygium surgery were as follows: Sim K astigmatism, $3.08 \pm 2.03 \mathrm{D}$ and $1.22 \pm$ $0.78 \mathrm{D}(P=0.001)$; irregularity at $3 \mathrm{~mm}, 3.49 \pm 1.66 \mathrm{D}$ and $1.95 \pm 1.08 \mathrm{D}(P=0.001)$; irregularity at $5 \mathrm{~mm}, 5.46 \pm 2.95 \mathrm{D}$ and $1.78 \pm 0.92 \mathrm{D}(P<0.001)$; mean refractive power at 3 $\mathrm{mm}, 43.2 \pm 1.17 \mathrm{D}$ and $44.5 \pm 1.34 \mathrm{D}(P=0.002)$; mean refractive power at $5 \mathrm{~mm}, 43.0 \pm 1.05 \mathrm{D}$ and $43.8 \pm 1.33 \mathrm{D}$ $(P<0.001)$. When the data was analyzed after dividing the patients into two groups according to the preoperative Sim K astigmatism, the patients with Sim K astigmatism $\geq 2 \mathrm{D}$ had a significant reduction in Sim K astigmatism after pterygium surgery; while those with Sim K astigmatism $<2$ D showed a statistically insignificant increase in Sim K stigmatism after surgery (Table 2). However, irregularities at $3 \mathrm{~mm}$ and $5 \mathrm{~mm}$ decreased in all subjects after surgery, regardless of preoperative Sim K astigmatism values.

Although the preoperative corneal astigmatism axis was found to lie with-the-rule in $58 \%$ of patients, against-the-rule in $17 \%$, and obliquely in $25 \%$, these frequencies shifted to with-the-rule in $28 \%$ of patients, against-the-rule in $42 \%$, and obliquely in 30\% at one month following surgery (Table 3). The "with-the-rule" astigmatism induced by the pterygium became "against-the-rule" astigmatism after pterygium removal $(P=0.041)$.

The results of contrast sensitivity testing conducted before and after surgery are shown in Figure 1. Contrast sensitivity values of 1.5 and $3 \mathrm{cpd}$ showed no significant changes after surgery. However, the values of 6,12 , and $18 \mathrm{cpd}$ increased significantly from $1.55 \pm 0.28,0.97 \pm 0.47$, and $0.29 \pm 0.16$ to $1.72 \pm 0.18,1.21 \pm 0.44$, and $0.65 \pm 0.48$, respectively $(P=0.007,<0.001$, and $<0.001$, respectively). A significant increase in contrast sensitivity at the spatial frequencies of

Table 3 Distribution of topographic astigmatic axes before and after pterygium surgery

\begin{tabular}{lll}
\hline & Preoperative & Postoperative \\
\hline With-the-rule & $21(58 \%)$ & $10(28 \%)$ \\
Against-the-rule & $6(17 \%)$ & $15(42 \%)$ \\
Oblique & $9(25 \%)$ & $11(30 \%)$ \\
\hline
\end{tabular}

6,12 , and $18 \mathrm{cpd}$ was observed after surgery both in the patients with Sim K astigmatism $\geq 2 \mathrm{D}$ and in those with Sim $\mathrm{K}$ astigmatism $<2 \mathrm{D}$.

\section{Discussion}

Several reports have previously demonstrated that pterygia cause corneal distortion and induce a significant amount of astigmatism. ${ }^{1-5}$ Most of those topographic changes in the cornea have been reported to be reversed by successful pterygium surgery, although eyes with advanced pterygia might not normalize completely. ${ }^{2-6}$ It has been previously reported that contrast sensitivity was lower at all spatial frequencies in the patients with pterygium. ${ }^{7}$ However, it remains unclear as to whether pterygium surgery can improve contrast sensitivity which has been decreased by the development of pterygium. This study was performed in order to evaluate the effect of pterygium surgery on contrast sensitivity as well as on corneal topographic changes such as astigmatism, irregularity, axis steepness, and refractive power.

Our results indicate that contrast sensitivity at mediumto-high spatial frequencies of 6,12 , and $18 \mathrm{cpd}$ significantly improved after pterygium excision, while contrast sensitivity at low spatial frequencies of 1.5 and $3 \mathrm{cpd}$ did not change after surgery. Contrast sensitivity at high spatial frequencies is reported to be involved in visual performance in daily life and in indoor activities such as face recognition. ${ }^{8,9}$ Hence, it is noteworthy that in our study, pterygium surgery caused a significant increase in contrast sensitivity at high frequencies. Although controversy exists regarding reproducibility of functional visual performance using contrast sensitivity with the Vistech chart used in our study, many reports have demonstrated the efficacy of this method for assessing functional visual performance in patients undergoing cataract and refractive surgeries. ${ }^{10-12}$ Therefore, our use of the Vistech chart has clinical relevance.

In our study, the mean Sim $\mathrm{K}$ astigmatism values decreased significantly after pterygium surgery in patients with preoperative Sim $\mathrm{K}$ astigmatism $\geq 2 \mathrm{D}$. However, the Sim K astigmatism tended to increase after surgery in the patients with preoperative Sim K astigmatism $<2 \mathrm{D}$, although the increase was not statistically significant. It is possible 

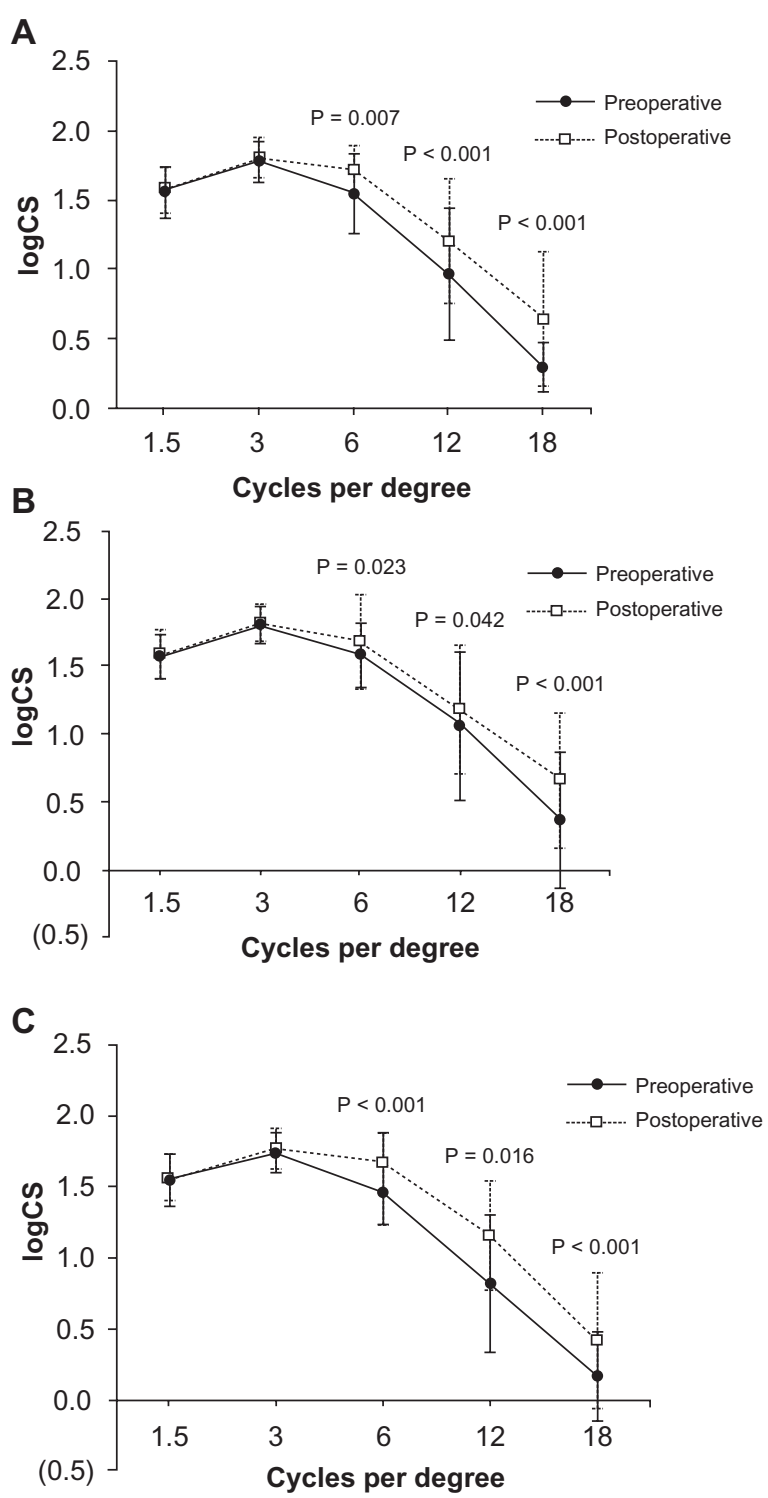

Figure I Comparison of contrast sensitivity before and after pterygium surgery. A) While contrast sensitivity values of 1.5 and $3 \mathrm{cpd}$ did not show any significant changes, the values of 6,12 , and 18 cpd increased significantly after surgery. B) A significant increase in contrast sensitivity at the spatial frequencies 6,12 , and 18 cpd after surgery was observed both in the patients with Sim $\mathrm{K}$ astigmatism $\angle 2 \mathrm{D}$ and C) in the ones with $\geq 2 \mathrm{D}$.

that the surgery itself might induce corneal topographical changes and that this effect becames more evident in the cases with less corneal astigmatism before surgery. Therefore, caution is necessary when planning pterygium surgery in patients with mild corneal astigmatism. Likewise, surgical intervention should be considered especially in patients with severe corneal astigmatism in order to improve visual quality. Corneal topography analysis is a valuable tool for evaluating the need for surgical intervention.

The topographic irregularities in the central 3 and $5 \mathrm{~mm}$ optical zones decreased in all patients after pterygium surgery. The change in irregularity values at $5 \mathrm{~mm}(67.4 \%)$ was greater than the change in irregularity values at $3 \mathrm{~mm}$ was (44.1\%). In addition, we found that surgical intervention resulted in an increase in the mean refractive power at one month after pterygium surgery, which indicates a steepening of the flattened cornea. We also noted corneal astigmatic axis change from with-the-rule to against-the-rule astigmatism at one month after surgery. This phenomenon can be explained by flattening of the cornea horizontally in the nasal quadrant, where the pterygium was located. This flattening effect dissipated after pterygium removal. ${ }^{1,3,4,13,14}$ However, a longer follow-up period is necessary in order to validate the corneal steepening effect of pterygium surgery. For instance, Ozdemir et al have reported that, astigmatic axes change return to with-the-rule at the postoperative late period (the third month), although the axes change from withthe-rule to against-the-rule and oblique at the postoperative early period (the second week). ${ }^{6}$

Our study was limited in that it was characterized by a short-term follow-up period after surgery. We evaluated the topographic values and contrast sensitivity in the first postoperative month. It is possible that corneal topography changes with time after surgery. As such, further studies with longer follow-up time are necessary.

In summary, our study demonstrates that successful pterygium surgery reduces corneal astigmatism and improves topographic irregularity. We found that optical qualities such as contrast sensitivity improved significantly after surgery. These effects were more apparent in the patients with preoperative Sim K astigmatism values greater than 2D. Corneal topography and contrast sensitivity values in patients with pterygia are useful either as indicators of the need for pterygium surgery or as indicators of surgical success.

\section{Acknowledgments/disclosures}

This material is not under consideration for any presentation and has not been previously presented in any meeting. The authors have not received grant support. No authors have any proprietary interests to disclose.

\section{References}

1. Yagmur M, Özcan AA, Sari S, Ersöz TR. Visual acuity and corneal topographic changes related with pterygium surgery. J Refract Surg. 2005;21:166-170.

2. Bahar I, Loya N, Weinberger D, Avisar R. Effect of pterygium surgery on corneal topography: a prospective study. Cornea. 2004;23: 113-117.

3. Yilmaz S, Yuksel T, Maden A. Corneal topographic changes after foue types of pterygium surgery. J Refract Surg. 2008;24:160-165. 
4. Cinal A, Yasar T, Demirol A, Topuz H. The effect of pterygium surgery on corneal topography. Ophthalmic Surg Lasers. 2001;32: 35-40.

5. Pesudovs K, Figueiredo FC. Corneal first surface wavefront aberrations before and after pterygium surgery. J Refract Surg. 2006;22: 921-925.

6. Ozdemir M, Cinal A. Early and late effects of pterygium surgery on corneal topography. Ophthalmic Surg Laser Imaging. 2005;36: 451-456.

7. Lin S, Reiter K, Dreher AW, Frucht-Pery J, Feldman ST. The effect of pterygia on contrast sensitivity and glare disability. Am J Ophthalmol. 1989;107:407-410.

8. Montes-Mico R, Charman WN. Choice of spatial frequency for contrast sensitivity evaluation after refractive surgery. J Refract Surg. 2001;17:646-651.

9. Ojanpaa H, Nasanen R. Utilisation of spatial frequency information in face search. Vision Res. 2003;43:2505-2515.
10. Reeves BC, Wood JM, Hill AR. Vistech VCTS 6500 charts-within- and between-session reliability. Optom Vis Sci. 1991;68:728-737.

11. Pesudovs K, Hazel CA, Doran RM, Elliott DB. The usefulness of Vistech and FACT contrast sensitivity charts for cataract and refractive surgery outcomes research. Br J Ophthalmol. 2004;88:11-16.

12. Niesen U, Businger U, Hartmann P, Senn P, Schipper I. Glare sensitivity and visual acuity after excimer laser photorefractive keratectomy for myopia. Br J Ophthalmol. 1997;81:136-140.

13. Oldenburg JB, Garbus J, McDonnell JM, McDonnnell PJ. Conjunctival pterygia. Mechanism of corneal topographic changes. Cornea. 1990;9:200-204.

14. Budak K, Khater TT, Friedman NJ, Koch DD. Corneal topographic changes induced by perilimbal lesions. Ophthalmic Surg Lasers. 1999;30:458-464.
Clinical Ophthalmology

\section{Publish your work in this journal}

Clinical Ophthalmology is an international, peer-reviewed journal covering all subspecialties within ophthalmology. Key topics include: Optometry; Visual science; Pharmacology and drug therapy in eye diseases; Basic Sciences; Primary and Secondary eye care; Patien Safety and Quality of Care Improvements. This journal is indexed on

Submit your manuscript here: http://www.dovepress.com/clinical-ophthalmology-journal

\section{Dovepress}

PubMed Central and CAS, and is the official journal of The Society of Clinical Ophthalmology (SCO). The manuscript management system is completely online and includes a very quick and fair peer-review system, which is all easy to use. Visit http://www.dovepress.com/ testimonials.php to read real quotes from published authors. 